\title{
Memória e história como
}

elementos para a TV Cult: o caso

da minissérie Queridos amigos

Clarice Greco ${ }^{1}$

1 Doutoranda e mestre em Ciências da Comunicação pela ECA-USP. Pesquisadora do Centro de Estudos de Telenovela (CETVN/ECA-USP) e do Observatório Iberoamericano de Ficção Televisiva (OBITEL). Bolsista FAPESP. claricegreco@usp.br. 


\section{Resumo}

O artigo analisa a relação do conceito de TV Cult com o resgate de uma memória coletiva a partir da época histórica retratada na ficção. Ao resgatar a memória nacional para criar uma obra ficcional televisiva, a produção é embebida de referências históricas e nostálgicas, podendo ser considerada um cult. Para a análise, são considerados elementos da série Queridos amigos, da Globo, que retratou o fim dos anos 1980 e a fase da ditadura militar com o intuito de provocar no público um movimento de memória e nostalgia, além de trabalhar internamente, na própria narrativa, o resgate da memória de personagens que refletem fatos reais da história do país. A análise é desenvolvida com base em teorias sobre ficção televisiva, memória e TV Cult.

\section{Palavras-chave}

TV Cult, ficção televisiva, memória, história, Queridos amigos.

\section{Abstract}

The article analyzes the relation between the concept of Cult TV and the rescue of a collective memory through television fiction based on historical time. When focused in national memories the television fiction is filled with historical and nostalgic references, so that it can be considered a cult production. This analysis considers elements from the miniseries Queridos amigos, production of Globo that portrays the end of the 1980's and the fase of military dictatorship willing to create a sphere of memory and nostalgia towards the public. Besides, it rescues inside the fiction the memories of characters that reflect real national history facts. The theoretical approach is based on notions of television fiction, memory and Cult TV.

\section{Keywords}

Cult TV, television fiction, memory, history. 
O presente artigo visa analisar a ficção como formadora de uma identidade nacional, tanto pela importância enquanto produto cultural frente à população brasileira quanto pela diversidade de temas e conflitos sociais que retrata em suas tramas. Entre a grande variedade de temas, formatos e gêneros apresentados pela ficção televisiva brasileira, um deles é o gênero histórico, que retoma temas da história nacional para retratar em forma de ficção. Segundo Kornis, entre os diferentes temas, especialmente pela Globo, destaca-se a tematização baseada em fatos da história brasileira recente que aparece representada nas minisséries, no que se chamou de "Séries Brasileiras" a partir de 1986, momento em que o país vive um processo de redemocratização (KORNIS, 2001).

Com foco nesse modelo de narrativa, este artigo analisa a relação entre história e memória, tomando esses elementos como base para uma ficção cult, a partir da minissérie Queridos amigos, da Rede Globo. A produção é assinada por Maria Adelaide Amaral e inspirada no livro Aos meus amigos, da mesma autora. O principal elemento que se destaca na minissérie Queridos amigos é a temporalidade da ficção. Transmitida pela Globo em 2008, a narrativa é ambientada em 1989 e conta a trajetória de um grupo de doze amigos que se consideravam uma "família" nos idos da Revolução do final dos anos 1970. Trata, portanto, de duas épocas distintas: o final dos anos 1980 e a segunda metade dos anos 1960, trabalhando intensamente a memória e o sentimento de pertencimento dos personagens a um episódio importante da história nacional.

Por assim se apresentar, e por se passar em uma época conturbada e comumente referida da história brasileira, a minissérie apresenta forte cunho histórico. Por outro lado, por constituir um grupo de personagens fictícios, com referências frequentes a fatos vividos por eles, eis aqui um elo entre ficção e história, entre ficção e memória nacional e entre história e memória. Essa abordagem do conteúdo a partir da temporalidade, nostalgia e apelo históricopolítico são elementos que podem pautar uma caracterização de programas da chamada TV Cult. Aqui, consideraremos essa série um cult por esses elementos, que serão discutidos a seguir. 
A estrutura do artigo se inicia com as bases teóricas sobre o conceito de TV Cult, a memória e a história nacional nas ficções brasileiras, noções que dialogam e pautam a análise baseada na minissérie, apresentada no final do texto.

\section{A TV Cult}

O termo TV Cult é utilizado em referência a determinados filmes ou séries televisivas que apresentem características específicas como estética original, narrativa inovadora ou uma legião de fãs que cultuam a ficção de forma fiel. Do ponto de vista teórico, a maior parte dos estudos referentes ao tema está concentrada nos Estados Unidos e Inglaterra, enquanto os autores alegam grande dificuldade em definir o termo. Hills (2010) acredita, no entanto, que haja um senso do que cult não é: não é vastamente popular, não é culturalmente onipresente, não é lugar-comum ou senso comum. Para ele, há algo de peculiar ou mesmo "underground" sobre o cult, que, por consequência, não é "pra qualquer um" (2010, p. 67). Roberta Pearson, após concordar sobre a tarefa árdua de expor seu significado, arrisca uma definição:

\footnotetext{
Na mídia, em uso comum e, às vezes até mesmo na academia, o termo cult é frequentemente aplicado a qualquer programa televisivo que seja considerado fora do padrão ou marginalizado, que atraia um nicho específico da audiência, que tenha apelo nostálgico, que seja considerado emblemático de alguma subcultura particular ou que seja descolado (2010, p. 7; tradução nossa).
}

Segundo a própria autora, o cult na TV concorda com o uso do termo no cinema, que se refere a filmes marginalizados, devido ao conteúdo forte ou ofensivo, normalmente relacionado a cenas de sexo ou violência, por serem de difícil acesso, principalmente na era anterior à internet, ou por serem consagrados por um núcleo de fãs que trabalhavam para assegurar a raridade e o valor do filme.

No cinema, alguns filmes são considerados cult por sua raridade, conteúdo filosófico ou crítica social, o que segrega o público e distancia o produto das 
classes mais populares. É o caso da minissérie Queridos amigos, que trata do tema da ditadura com forte crítica aos tempos da censura, tortura e exílio, que marcaram profundamente a vida dos personagens (tanto os da ficção quanto os brasileiros). Essas características distinguem os produtos de tal forma que é possível encontrar, em locadoras, a classificação de certos títulos como "filmes cult" ou "filmes de arte". Eco (1985), a exemplo de Casablanca, afirma que o filme não é uma obra de arte, pelo contrário, possui um alcance estético bastante modesto. Contudo, o filme é ao mesmo tempo "um ótimo exemplo de discurso cinematográfico, um palimpsesto para os futuros estudantes da religiosidade do século $\mathrm{XX}$, um sumo laboratório para pesquisa semiótica em estratégias textuais. Ademais, se tornou um filme cult" (ECO, 1985, p. 3). Notase, portanto, que no cinema é comum que esse caráter demande um tempo de maturação da obra para que seja conquistado. Esses filmes acabaram por conquistar seu lugar na história do cinema e são, muitas vezes, atemporais; isto é, conseguem emitir sua mensagem narrativa ou estética em qualquer época.

No Brasil, pela história recente do cinema brasileiro, a maioria dos filmes do século XX apresenta características de obras cult, como a raridade e dificuldade de acesso público, a audiência reduzida e bastante específica, as narrativas pouco envolventes com cenas fortes de violência e sexo, apelo regional e histórico ou estilo documental, além da produção com orçamento precário, que prejudicava a estética dos filmes, dando a eles hoje um ar de vanguarda. Os filmes que tratam de temas históricos, que são raros ou que apresentam imagens em preto e branco indicando que são do início do cinema brasileiro, normalmente adquirem um caráter cult, por possuir público reduzido e específico, apreciadores ou estudiosos de cinema.

Umberto Eco (1985) sugere três critérios para um filme ser cult: 1) deve ser apreciado por ao menos um pequeno grupo de fãs; 2) prover um mundo completo e mobiliado para que os personagens e cenários possam ser citados pelos fãs como se estes o habitassem; e 3) ser composto de segmentos de história que possam ser lidos, vivenciados e recordados, independentes do todo. 
Interessante ressaltar que Eco escreveu esse ensaio antes da internet, com base na hipertextualidade que deu origem à transmidialidade hoje possibilitada mais facilmente pelas novas mídias. Um quarto elemento dos filmes cult é ressaltado por Eco, não como critério a ser cumprido, mas como característica presente em filmes que já nascem com a proposta de se tornarem cult: as citações ou menções de outros filmes embutidas na narrativa. Segundo o autor, os filmes que se propõem a uma narrativa rebuscada surgem, muitas vezes, com um nível consciente de intertextualidade que dificilmente o telespectador acompanha. A intertextualidade é bem sucedida quando a cena pode ser desfrutada e compreendida independente do conhecimento do espectador a respeito de outras obras ou diretores. Também as ficções televisivas, quando referidas como cult, são dotadas das mesmas características presentes no cinema cult, de onde o termo foi herdado.

Dentro dessas diretrizes, a análise deste artigo segue a noção de cult como história a ser relembrada e com elementos de referência a outros filmes, estendendo-se a outras referências gerais, como músicas, livros e fatos da realidade. Essas referências, presentes nos filmes cult, são uma estratégia para unir o público específico de audiência ao qual o cult se refere, utilizando o artifício da memória para angariar fãs, que se identificam com as menções presentes na narrativa.

Assim, dentre um universo de ficções televisivas com as características acima mencionadas, este artigo volta os olhares à minissérie Queridos amigos para uma análise dos elementos históricos e de memória que ajudam a caracterizar a ficção. Alguns desses elementos são o nicho específico de público, o retorno constante ao passado, as referências culturais, a utilização de arquivos históricos e a base ficcional que retorna a um tempo real do país - a fase da ditadura militar - que une o núcleo central de personagens. Os diálogos são comumente bem detalhados e trabalhados com riqueza de linguagem, em tratamento de temas com maior teor intelectualizado do que as tradicionais ficções, também a caracterizando cult por conter referências 
que não serão compreendidas por todo e qualquer público. Os elementos narrativos da ficção serão mais detalhados após a passagem teórica a seguir, que intenciona relacionar os aspectos da ficção mencionados como cult aos estudos sobre história e memória.

\section{Ficção televisiva, história e memória}

Tomando como ponto de partida a noção de uma ficção cult com base nos critérios do apelo nostálgico, das referências e do conteúdo destinado a um público específico, pode-se dizer que o tratamento de um tema histórico adaptado à ficção traz elementos que se relacionam teoricamente com os estudos de história e memória. A ficção televisiva de cunho histórico está fortemente ligada ao caráter histórico de produções (ficção ou documentário) que surgiam no início do cinema brasileiro. Esse movimento pelo resgate da memória histórica e da nacionalidade brasileira na ficção televisiva sustenta uma relação próxima ao cinema. Desde o início das produções brasileiras, eram comuns filmes que retratassem a história nacional de forma ficcionalizada, como Descobrimento do Brasil (Humberto Mauro, 1937), e O cangaceiro (Lima Barreto, 1953), considerado um marco da Companhia Cinematográfica Vera Cruz. Nos anos 1970, o cinema foi impulsionado pelo financiamento de filmes literário-históricos pela Embrafilme, a exemplo de Independência ou morte (Carlos Coimbra, 1972) e Dona Flor e seus dois maridos (Bruno Barreto, 1975) (ORTIZ; BORELLI; RAMOS, 1991, p.88). A partir desse movimento, da transição de autores do teatro e do cinema para a televisão e da proximidade entre os dois meios, a partir da década de 1980, o tema passou a ser fortemente tratado pelas ficções televisivas.

A primeira minissérie a retratar uma época histórica foi Anos dourados, exibida em 1986 pela Globo, que se passava no período do governo de Juscelino Kubitschek (KORNIS, 2001). Desde então, tornou-se cada vez mais comum que minisséries nacionais, especialmente as produzidas pela Globo, abordassem 
temas e temporalidades históricas como forma de resgate da memória nacional por meio do melodrama. Nos anos 2000, a tradição segue com outras produções da Globo como, por exemplo, A casa das sete mulheres (2003), Dalva e Herivelto (2010) e Queridos amigos (2008).

É importante também esclarecer que não é aqui descartada a noção de que qualquer ficção poderia ser considerada histórica por referir-se a uma realidade da qual faz parte. A história está presente no tempo da narrativa. No entanto, segundo Morettin (1993),

existem filmes onde a ação se ambienta claramente no passado. A sua narrativa, nesses casos, recorre a uma série de estratégias para situar a trama nesse período. Estas estratégias se manifestam na escolha do tema e/ou "herói" (...), nos trajes das personagens, nos cenários por onde se desenrola a ação e na indicação da localização temporal de seu entrecho (1993, p. 251).

A minissérie Queridos amigos possui características que a encaixam nessa definição, podendo-se considerar o aspecto histórico da narrativa por seu esforço em reproduzir uma época que não a que foi transmitida, o que exige figurino próprio de um período anterior e outros elementos necessários para a localização temporal da ficção no ano em que se passa - no caso, 1989. Especialmente por retratar uma época próxima, o telespectador facilmente crê que a narrativa se situa no tempo atual em que assiste, até que note as vestimentas pouco atuais, a falta de telefones celulares na urgência em se localizar um personagem, comentários sobre a disputa entre Lula e Collor nas eleições ou quando é mencionada uma reprise de Que rei sou eu, elementos que fixam a temporalidade da trama.

Ao chamar tais ficções de "históricas", procuramos não aprofundar a questão sobre a história ser, ela própria, uma ficção. Valemo-nos da análise de como o tratamento histórico foi abordado e qual a sua função dentro do contexto narrativo. Mas temos em mente que tanto o filme quanto a ficção televisiva carregam em si potencial para serem objetos de estudo da história e da memória. 
Podemos contrapor duas visões sobre os efeitos da mídia e da memória. Nora (1993) acredita no fim das sociedades-memória, acusando a mídia de dilatar a percepção histórica e substituir "uma memória voltada para a herança de sua própria intimidade pela película efêmera da atualidade" (p. 8). Não crê nos artifícios da mídia como responsáveis por transmissão de valores e arquivos de memória social. Por outro lado, tomando o cinema como uma mídia poderosa, Ferro (1976) o defende ao dizer que o postulado para o cinema como história é que "aquilo que não se realizou, as crenças, as intenções, o imaginário do homem, é tanto a História quanto a História". E, por fim, afirma que o filme não é considerado "um produto, uma imagem-objeto, cujas significações não são somente cinematográficas. Ele vale por aquilo que testemunha" (FERRO, 1976, p. 200). Para a televisão, é o caso de telenovelas e séries cujo tema central não é necessariamente um retrato fiel da realidade, mas a moda, as expressões ditas e traços do comportamento que testemunham um contexto histórico, o que dá ao produto uma carga de memória relevante.

Nesse debate, tendemos a concordar com Ferro, apoiando a ideia de que as mídias proporcionam um retorno ao passado e alimentam um repertório de história e memória coletiva, no qual bebem os sujeitos para alimentar suas memórias individuais. Halbwachs (2006) associa a memória do indivíduo à memória do grupo, e esta à memória coletiva de sua sociedade. Segundo o sociólogo, que estuda os quadros sociais da memória, as lembranças não ficam restritas a um mundo individual. Elas são moldadas pelo grupo. É como o indivíduo que busca no YouTube as cenas inesquecíveis de seus filmes ou telenovelas prediletos, episódios jornalísticos marcantes ou gols irrepetíveis. As cenas fazem parte de um arquivo ao mesmo tempo pessoal e coletivo e, como tal, são retratadas e reproduzidas pela mídia a fim de eternizá-las. Conforme definido por Nora, "a história é a reconstrução sempre problemática e incompleta do que não existe mais. A memória é um fenômeno sempre atual, um elo vivido no eterno presente; a história, uma representação do passado (1993, p. 9)". Se é assim, o elo entre a história e a memória está exatamente na reconstrução 
incompleta do que não existe mais sendo revivida no eterno presente - hoje, com a ajuda imperativa da mídia.

A partir dessas premissas, e tomando-se a ficção televisiva como narrativa da nação (LOPES, 2009) por pautar-se na realidade e na proximidade cultural brasileira, chega-se ao que Nora chamou de perda da memória nacional, uma vez que acredita que a nação "não é mais o quadro unitário que encerrava a consciência da coletividade (...), a nação não é mais um combate, mas um dado; a história tornou-se uma ciência social; e a memória um fenômeno puramente privado" (NORA, 1993, p.12). As ficções televisivas confrontam essa visão pessimista, uma vez que a audiência reunida em torno da TV pode constituir um quadro unitário que encerra a consciência da coletividade.

A ficção, ainda, ao renovar aspectos da memória é responsável por tornála novamente um fenômeno coletivo. Essa visão vai de encontro aos dizeres de Morettin (1993), ao afirmar que o fio condutor que agrupa os elementos que compõem o cinema é a ideia de que "se constrói uma nacionalidade a partir da experiência cinematográfica" (1993, p. 249). O mesmo efeito pode ser resultado da ficção e da experiência do telespectador.

\section{Memória afetiva e história nacional na minissérie Queridos amigos}

Primeiramente, é importante frisar uma questão de natureza epistemológica: o lugar da pesquisadora em relação ao objeto. Estudiosa das teorias e métodos de pesquisa em ciências da comunicação, a proximidade teórica perpassa antes a recepção e a análise do discurso do que a perspectiva semiótica. Desse modo, a análise é voltada especialmente à narrativa, ao conteúdo e a sua relação com a temática histórica, com menos foco nos elementos estéticos.

Tomando como ponto de partida a noção de uma ficção cult com base nos critério do apelo nostálgico, do tema histórico e do conteúdo destinado a um público específico, aprofundamos agora o objeto de análise deste artigo: a 
minissérie Queridos amigos, produzida e exibida pela Globo, em março de 2008. A narrativa, ambientada em 1989, relata a amizade de doze personagens que foram engajados na luta contra a ditadura, no final dos anos 1970. Partilhavam dos mesmos ideais e agora, 20 anos depois, vivem suas vidas com diferentes graus de afastamento dos sonhos que alimentavam quando jovens.

Assim, um dos elementos que concedem maior especificidade à minissérie Queridos amigos é o uso de uma memória dupla: a primeira, relativa ao tempo histórico diegético, que remete a 1989, quando a esperança nas eleições diretas que viriam a eleger o presidente Collor era a pauta dos assuntos dos politizados personagens; e a segunda, do final dos anos 1960, quando os amigos relembram seu passado, que inclui a realidade brasileira do regime militar e também dos personagens, dos amores e desentendimentos entre eles. Ambas as épocas remetem a fatos marcantes da história do país, caracterizando temporalmente a minissérie como histórica. Essa construção aponta claramente a intenção de memória histórica impingida na ficção. A análise se volta para os dois primeiros episódios da série, que abrangem o início das preparações até o fim da festa de Léo, uma reunião dos amigos que vivenciaram a ditadura militar. O recorte é necessário, pois uma minissérie, diferentemente de um filme, é apresentada em 25 capítulo e cerca de 18 horas, o que torna inviável a análise da obra completa em um artigo dessas dimensões. O motivo dessa seleção se justifica por ser o trecho no qual se concentra o maior número de referências históricas e de memória coletiva. A análise perpassa esses elementos a partir do olhar sobre um programa cult, que utiliza da memória afetiva e desses elementos históricos e intelectuais para se caracterizar como tal.

A cena inicial da minissérie deixa claro o seu foco para um público acima de 50 anos, que teria vivenciado a entrada da década de 1990 com fortes lembranças da ditadura militar, acrescido do público jovem-adulto que estudou o assunto, compreende esse período da história nacional e possui fortes referências musicais e fílmicas. A primeira tomada do primeiro capítulo da minissérie mostrou cenas de protestos, de filmes clássicos, fotos e cartazes 
antigos em referência ao passado brasileiro e internacional, ao som de Cry baby, de Janis Joplin. Em seguida surge na tela o Porshe 911T preto do personagem Léo, a câmera adentra o veículo e acompanha a mão de Léo ao rádio do carro, alterando a música para Born to be wild, por Steppenwolf. Tais referências nostálgicas ao nicho de público que irá compreendê-las evidenciam, segundo ECO (1985), as características de um programa cult. O foco volta a mostrar a estrada, situando a narrativa em um tempo em que as pessoas tinham fortes ideais e lutavam por liberdade. A câmera inicia forte movimentação, para o alto ou em círculos, agitação que se acentua até que o carro cai da ponte em um rio. O personagem, enquanto afunda, passa a ver cada um de seus velhos amigos dentro da água. O acidente fora um sonho que deu o pontapé inicial à ficção. Esse trecho já remete ao afeto, essência da memória afetiva - tanto dos personagens quanto do público telespectador.

A partir de então, o personagem Léo, que sofre de uma doença grave que lhe concede pouco tempo restante de vida, decide aproximar novamente os amigos, que se chamavam "família" na época em que lutaram juntos pelo fim da ditadura militar. Porém, esses amigos levam vidas distintas, alguns casados, outros com filhos, outros solteiros, alguns ricos e alguns com empregos miseráveis, depressivos ou não, em suas realidades afastadas do período turbulento que vivenciaram em outros tempos. Esses personagens ensejam indivíduos como os telespectadores, que com o andar da vida cotidiana se esquecem do seu passado. Léo surge para resgatar isso em todo o público.

Para além dos conflitos pessoais de cada um, o personagem Léo resolve dar uma festa para reunir o grupo. Vai pessoalmente convidar cada um dos 11 personagens que aceitam, alguns relutantemente, o convite. Essas visitas duram o primeiro episódio inteiro e baseiam-se nas conversas de cada personagem com Léo, nas quais já recuperam memórias, por serem amigos que não se viam há tempos. Dessa forma, os demais personagens são introduzidos na trama, já bem caracterizados, assim como o estilo nostálgico da própria ficção. 
Seguem-se os preparativos para a festa de Leo e a chegada dos amigos. Nessa festa ocorre uma série de turbulências, causadas por diferenças que surgiram ou se acentuaram entre cada indivíduo particular, já que agora habitam mundos distantes entre si. À mesa do almoço, os comentários giram em torno do final dos anos 1980, com um discurso que resgata a esperança que população brasileira sentia na recuperação do país em crise. As falas dos personagens esperançosos causam em quem assiste um misto de nostalgia daquela felicidade, pelas lembranças pessoais de quem acreditou que as eleições de 1989 fossem mudar o Brasil, e de tristeza, por já conhecermos o futuro e sabermos que se seguiu a isso um grande desastre da política nacional, com a eleição de Fernando Collor de Mello e seu impeachment.

A conversa ao redor da ampla mesa posta no belíssimo jardim de Léo termina de vez com a chegada de Beni, homossexual milionário que traz como acompanhante um travesti. Aqui, há a retomada do discurso do preconceito contra os homossexuais, muito forte no final da década de 1980. A narrativa contempla com importância suficiente o intenso debate sobre a AIDS, o medo da doença e a dificuldade de se assumir gay, assuntos polêmicos da época. Beni chega provocando cada um dos amigos, falando verdades e grosserias, o que dá um trágico fim ao almoço "feliz" idealizado por Léo.

À tarde, ainda na casa de campo após o almoço fracassado, chega o momento de maior historicidade da ficção, quando Bia (Denise Fraga) pergunta a Tito: "Sabe que dia é hoje?" E ele lembra: Faz 10 anos que nós voltamos do exílio!". A fala, em referência à volta do exílio de várias personalidades brasileiras ocorrida em 1979, dá partida à primeira e principal cena com resgates de arquivo histórico da minissérie. Um dos amigos coloca um vídeo para assistirem na televisão, do dia de festa, alegre, que registra a volta dos exilados. Os flashes em preto e branco misturam ficção e realidade, em um marcante momento histórico, misturando imagens de arquivo e encenações fictícias. As cenas mostram abraços dos personagens da narrativa, em preto e branco, simulando serem "reais", intercaladas a imagens de arquivo de "personagens reais", 
documentadas pela Globo no dia da volta dos exilados em 16 de setembro de 1979, entre uma multidão com cartazes de protesto e entrevistas concedidas por Henfil e Betinho. As referências que requerem um público seleto são nítidas. A construção da passagem é criada com esmero, completa, detalhada. A trilha sonora não poderia ser mais apropriada, com Elis Regina cantando $O$ bêbado e a equilibrista, combinando as cenas com a letra "meu Brasil... que sonha com a volta do irmão do Henfil, com tanta gente que partiu...".

O trecho da minissérie a insere na classificação de ECO (1985) de que um programa cult deve ser composto de segmentos de história que possam ser lidos, vivenciados e recordados. Aqui, a documentação apresentada pela ficção vai além da afirmação de Ferro de que "... um filme, qualquer que seja, sempre excede seu conteúdo" (1976, p. 213) em relação à documentação natural de época ou ao momento em que a produção se insere. Mais do que isso, a passagem recria um documentário dentro da ficção, perto de caracterizar o formato docudrama. Segundo Santos (2010), o docudrama é um gênero audiovisual híbrido composto por convenções formais do documentário com o melodrama. O que diferencia Queridos amigos de um docudrama, segundo os pressupostos de Santos (2010), é a base da minissérie em uma narrativa ficcional, ao invés de uma reconstituição de fatos reais como base narrativa. No entanto, apresenta-se como formato híbrido que mescla documentação e realidade, ligada ao processo histórico e de memória nacional, fortalecendo o caráter cult da série.

A passagem confirma, ainda, seu status cult relativo à memória por ser completamente emocional e nostálgica. Trabalha três tipos de memória: a memória diegética da ficção, com os personagens relembrando as cenas de suas vidas, a memória sócio-histórica, pelas imagens de arquivo exibidas e a memória nacional afetiva, pelo reviver de um momento marcante de luta e vitória dos cidadãos brasileiros que se sacrificaram pelo País. 
O caráter cult é visível na minissérie também em outros momentos, como em referências intelectuais a teorias comunistas que saltam dos diálogos dos personagens. Um exemplo claro se dá quando o personagem Pedro, um escritor falido desde que entrou em depressão pela morte da mulher, alega: "não sou mais classe média, sou lumpen".2 Aqui, mostra-se o elemento ressaltado por ECO (1985) para filmes que nascem com o intuito de se tornarem cult - a menção a outras obras, fator que limita a plena compreensão do diálogo apenas aos telespectadores que tenham conhecimento da obra de referência. No caso, a teoria de Marx e Engels.

Por fim, o momento de assistência ao vídeo culmina em uma briga entre Tito (ex-marido de Vânia, que continua com fortes traços socialistas) e Fernando (empresário capitalista, atual marido de Vânia). A festa torna-se um fracasso perante o objetivo de Léo, que era o de resgatar os afetos. Enquanto os personagens se lamentam, Léo vai ao jardim conquistar o filho que abandonou quando bebê, fazendo mágicas e soltando balões de gás para o céu. Nesse momento, pouco a pouco, os outros amigos vêem os balões coloridos ocupando o céu azul e se aproximam do jardim. Quando todos estão reunidos no imenso gramado, vem a chuva, elemento típico de mudança. Todos dançam na chuva, simbolizando a alegria e a paz entre os indivíduos. Assim se encerra a festa de Léo, que gera a reaproximação dos amigos e uma série de conflitos e dramas que prosseguem na ficção.

\section{Considerações finais}

Se alguns dos elementos para uma TV Cult são a audiência sofisticada, o apelo nostálgico, as referências a outras obras e a sua temporalidade, Queridos amigos pode ser considerada um cult. Voltada a um público que deveria absorver

2 O termo alemão significa, ao pé da letra, "homem trapo" e foi introduzido por Marx e Engels em A ideologia alemã (1845). No vocabulário marxista, se refere à fatia da população de classe social abaixo da operária, com ínfimas condições de vida e de trabalho, sem recursos financeiros e pouca consciência política sendo, portanto, considerados seres desprezíveis e suscetíveis de servir aos interesses da burguesia. 
referências como AI-5, Diretas Já, Manifesto Comunista, Chico Buarque e Janis Joplin, a minissérie surgiu para despertar telespectadores não comumente ligados nas ficções da TV Globo. Isso pode explicar o que Hills queria dizer com "não é 'pra qualquer um'" (2010, p.67).

Além disso, a minissérie se encaixa na classificação de séries históricas (KORNIS, 2001) e traz elementos de memória afetiva, memória coletiva (Halbwachs, 2006) e de lugares entre memória e história (NORA, 1993). Esses elementos ajudam a classificar a obra como um cult, mas, principalmente, fazemna cumprir a função de televisão informativa, com abordagem diferenciada, que incentivou a abertura a um novo gênero híbrido que coleciona fatores relevantes da nossa memória e da história nacional. 


\section{Referências}

ECO, U. "Casablanca: Cult Movies and Intertextual Collage". SubStance, v. 14, n. 2, Issue 47: In Search of Eco's Roses, 1985.

FERRO, M. "O filme: uma contra-análise da sociedade?". In: LE GOFF, J. e NORA, P. História: Novos Objetos. Tradução de Terezinha Marinho. Rio de Janeiro: Francisco Alves, 1976.

HALBWACHS, M. A memória coletiva. São Paulo: Centauro Editora, 2006.

HILLS, M. "Mainstream Cult". In: ABBOT, Stacey (ed.). The Cult TV book: from Star Treck to Dexter, new approaches to TV outside the box. New York: Soft Skull Press, 20 10.

KORNIS, M. A. "Uma memória da história nacional recente: As minisséries da Rede Globo". Anais da XXIV Congresso Brasileiro da Comunicação da INTERCOM - Sociedade Brasileira de Estudos Interdisciplinares da Comunicação. Campo Grande/MS, setembro de 2001.

LOPES, M. I. V. "Telenovela como recurso comunicativo". Revista MATRIZEs, ano 3, n.1, ago/dez 2009.

MORETTIN, E. V. "A representação da história no cinema brasileiro". Anais do Museu Paulista: História e Cultura Material, v.1, 1993.

NORA, P. "Entre memória e história: a problemática dos lugares". Projeto História: Revista do Programa de Estudos Pós-graduados em história e do Departamento de História. PUC/SP, n. 10, dezembro de 1993.

ORTIZ, R.; BORELLI, S. H. S. e RAMOS, J. O. Telenovela: história e produção. São Paulo: Brasiliense, 1991. 
PEARSON, R. "Observations on Cult television". In: ABBOT, S. (ed). The Cult TV book: from Star Treck to Dexter, new approaches to TV outside the box. New York: Soft Skull Press, 2010.

SANTOS, A. T. Ficção e antificção na telenovela brasileira: a hibridação do formato e a aproximação com o gênero docudrama. Tese (doutorado). Escola de Comunicação e Artes da Universidade de São Paulo, São Paulo, 2010. 